\title{
Bidding Strategy of Virtual Power Plant with Energy Storage Power Station and Photovoltaic and Wind Power
}

\author{
Zhongfu Tan $(\mathbb{D}$, Qingkun Tan $(\mathbb{D}$, and Yuwei Wang $(\mathbb{D})$ \\ School of Economics and Management, North China Electric Power University, Beijing 102206, China \\ Correspondence should be addressed to Zhongfu Tan; tanzhongfubeijing@126.com
}

Received 19 October 2017; Revised 27 January 2018; Accepted 8 February 2018; Published 1 April 2018

Academic Editor: Yuh-Shyan Hwang

Copyright (C) 2018 Zhongfu Tan et al. This is an open access article distributed under the Creative Commons Attribution License, which permits unrestricted use, distribution, and reproduction in any medium, provided the original work is properly cited.

For the virtual power plants containing energy storage power stations and photovoltaic and wind power, the output of PV and wind power is uncertain and virtual power plants must consider this uncertainty when they participate in the auction in the electricity market. In this context, this paper studies the bidding strategy of the virtual power plant with photovoltaic and wind power. Assuming that the upper and lower limits of the combined output of photovoltaic and wind power are stochastically variable, the fluctuation range of the day-ahead energy market and capacity price is stochastically variable. If the capacity of the storage station is large enough to stabilize the fluctuation of the output of the wind and photovoltaic power, virtual power plants can participate in the electricity market bidding. This paper constructs a robust optimization model of virtual power plant bidding strategy in the electricity market, which considers the cost of charge and discharge of energy storage power station and transmission congestion. The model proposed in this paper is solved by CPLEX; the example results show that the model is reasonable and the method is valid.

\section{Introduction}

The randomness and fluctuation of the wind and photovoltaic power output restrain its grid connected capability $[1,2]$. In 2016, China's wind and photovoltaic power installed capacity was $182.15 \mathrm{GW}$, which ranked first in the world, but the amount of wind power curtailment electricity reached $20 \mathrm{TW} \cdot \mathrm{h}$. The average number of hours of wind power utilization was $1728 \mathrm{~h}$, especially in the "Three-North" area of China, where the wind and solar energy resource is relatively abundant and the equivalent utilization time of wind power is only about $1445 \mathrm{~h}$. In order to achieve large-scale wind power integration, the system needs to arrange reserve services for wind and photovoltaic power, mainly including conventional thermal power units, pumped storage power stations, and energy storage power stations. As the environmental pressure reduction and transmission capacities caused storage power station reserve services inapplicability, this will limit the energy storage station providing the reserve service for wind and photovoltaic power. This paper constructs a virtual power plant with energy storage power station and photovoltaic and wind power which bids in the electricity market, maximizes the benefit of virtual power plant, and promotes the grid-connected generation of photovoltaic and wind power.

In recent years, many scholars have carried out research on the influencing factors of new energy utilization. Nick et al. [3] and Al Kaabi et al. [4] proposed the concept of generating units-power grid-system load interaction, which can effectively reduce the operation cost of the system and promote the grid-connected generation of wind power. $\mathrm{Wu}$ et al. [5] used demand side management and storage technology and construct power dispatching model with wind power and energy storage; Georgilakis and Hatziargyriou [6] established a day-ahead market clearing model of wind power based on demand side management, which provided a reasonable operation mechanism for the marketization of wind power. Sadeghi-Barzani et al. [7] established twostage demand response of stochastic programming model with the wind power to maximize the lower cost of the demand response and enhance grid-connected capacity of wind power. Zhipeng et al. [8] considered price demand response and security constraints, where the system scheduling cost minimization was objective function, and established real-time optimization scheduling model. Huajie et al. [9] proposed regional and provincial two-level optimization 
scheduling model by adjusting the conventional unit output and interprovincial electricity trade balance wind power output; results show that the model could enhance gridconnected capacity of wind power. Binato et al. [10] proposed a new calculation method to reduce the amount of wind power curtailment in the peak period of the grid. Xiaogang et al. [11] established a dual-objective scheduling model with wind power, based on the second-generation noninferior dominating sorting genetic algorithm. Muñoz-Delgado et al. [12] considered the thermal power, hydropower and wind power, electric and heating load balance, and transmission capacity constraints, with operation cost minimization of the system as the objective function, and set up wind power grid-connected analysis model. The above literatures focus on the multiobjective optimization of wind power system and the improvement of the scheduling model. But the actual situation of China's large-scale wind power centralized access only using these techniques is not enough.

Robust optimization theory is a tool to solve the problem of uncertainty [13, 14]. Haffner et al. [15] introduced the uncertainty set to the large-scale photovoltaic power optimal scheduling systems to make up for the conservative optimization of the box set to partial conservative. Wen and Kumar [16] introduced the game model into the robust optimization problem of the power system and obtained an economic scheduling strategy with strong robustness to short-term uncertainty of wind power generation. Ruozhen et al. [17] introduced the dual theory into the multiperiod inventory robust optimization model; the convex programming problem could be easily solved, which could effectively restrain the influence of the uncertainty of demand distribution on the effectiveness of the strategy. Wen and David (2001) [18] adjusted the boundary of the uncertain set to control the conservativeness of the robust optimization model and realized the economic and security balance of the decision. Pandžić et al. [19] proposed a robust optimization method based on moment uncertain distribution to solve the problem of economic and environmental scheduling with wind power. Kirschen et al. [20] optimized the power flow calculation of distribution network with the strong duality theory; the robust optimization model was transformed into mixed-integer linear programming to compensate for the shortcomings of robust optimization conservatism. Haipeng et al. [21] transformed a two-layer deterministic optimization model into double-layer optimization method, which was optimized by interior point method and had good engineering practicality. Ling et al. [22] introduced the sorted truncation method to improve the efficiency of the solution. Feng et al. [23] proposed an improved robust model for the problem of uncertainty on the right side, which improved the efficiency of the solution. Qiang et al. [24] proposed the scheduling model of the wind power system based on the robust optimization framework, which solved the problem of the objective function deterioration.

In electricity market bidding, Chao et al. [25] proposed a competitive bidding mechanism of the power market with both the supply and demand sides. Peiyi and Xinyan [26] took minimization of purchase cost as the objective function and proposed a bidding method of electricity market based on genetic algorithm. Zheng et al. [27] proposed the formation price mechanism and bidding strategy of renewable energy power generation and analyzed the influence of renewable energy on the electricity market bidding. Jianxue et al. [28] established mixed bidding model of power market, which solved the difficulty of dealing with sub-time constraint and improved the feasibility of the market clearing result. Li et al. [29] analyzed the competition psychology of the power supply market participants with the game theory and established the bidding strategy under different conditions. Yixin et al. [30] analyzed the bidding method of the electricity market in the power supply side with the participation of the microgrid and determined the optimal bidding strategy of the microgrid operators in the alliance and nonalliance. Long et al. [31] analyzed the relationship between the pricing mechanism, the energy substitution, and the bidding strategy and obtained the optimal strategy of the integrated energy sales company to participate in the market bidding purchase. Carrión and Arroyo [32] proposed a transferable bid strategy based on the autoregressive integral moving average mode. Mashhour and Moghaddas-Tafreshi [33] established the profitability model of the electricity sales company under the deviation assessment mechanism and constructed the optimal purchase model of the interruptible load with the minimum cost of the evaluation. Raab et al. [34] introduced the multiagent technology into bidding and optimization scheduling of the virtual power plant, which increased the distributed power generation participating in the electric power transaction.

As a method to deal with the uncertain factors, robust optimization has been paid more attention in many fields such as natural science and engineering technology. On the above background, this paper takes the virtual power plant to maximize the economic benefits as the objective function and the virtual power plant output and market price as uncertainties and constructs the virtual power plant bidding strategy robust optimization model with energy storage station and photovoltaic and wind power.

\section{Unit Output Model}

2.1. Wind Power Output Model. Wind turbine power is subject to the wind speed, but if the wind speed is lower than the cut-in speed or higher than the cut-out speed, wind turbines cannot generate electricity; the relationship between wind turbines power and wind speed is as follows:

$$
\begin{aligned}
& g_{j, w}(t) \\
& = \begin{cases}0, & v(t) \leq v_{i, w} \text { or } v(t)>v_{o, w} \\
g_{r}\left(v(t)-v_{i, w}\right)\left(v_{r, w}-v_{i, w}\right), & v_{i, w} \leq v(t) \leq v_{r, w} \\
g_{r}, & v_{r, w} \leq v(t) \leq v_{o, w},\end{cases}
\end{aligned}
$$

where $g_{j, w}(t)$ is the output of $j$ wind turbine at time $t ; g_{r}$ is the rated power of wind turbine; $v_{i, w}, v_{o, w}$ are the cut-in speed and the cut-out speed of wind turbine; $v_{r, w}$ is the rated speed of wind turbine; $v(t)$ is the speed of wind turbine at time $t$. 
2.2. Photovoltaic Power Model. The output curve of photovoltaic power system generally satisfies the Beta distribution; the specific formula is as follows:

$$
\begin{aligned}
& f(\theta) \\
& = \begin{cases}\frac{\Gamma(\alpha) \Gamma(\beta)}{\Gamma(\alpha)+\Gamma(\beta)} \theta^{\alpha-1}(1-\theta)^{\beta-1}, & 0 \leq \theta \leq 1, \alpha \geq 0, \beta \geq 0 \\
0, & \text { else, }\end{cases}
\end{aligned}
$$

where $\alpha, \beta$ are the parameters of the Beta distribution; $\theta$ is the radiosity correlation coefficient; the parameters of Beta are calculated by formula (3) as follows:

$$
\begin{aligned}
& \beta=(1-\mu) \times\left(\frac{\mu \times(1+\mu)}{\delta^{2}}-1\right) \\
& \alpha=\frac{\mu \times \beta}{1-\mu},
\end{aligned}
$$

where $\mu$ is the mean and normal distribution of solar radiation; $\delta$ is the variance of solar radiation; the probability of solar radiation can be calculated by the following formula:

$$
P(\theta)=\int_{\theta_{c}}^{\theta_{d}} f(\theta) d \theta,
$$

where $P(\theta)$ is the radiation intensity; $\theta_{c}, \theta_{d}$ are the upper and lower limits of solar radiation $\theta$; the formula for calculating the conversion of solar radiation into electrical energy is as follows:

$$
g_{m, \mathrm{pv}}(t)=\varepsilon \times P(\theta) \times S_{\mathrm{pv}} \times \theta_{t},
$$

where $S_{\mathrm{pv}}$ is area of photoelectricity; $\theta_{t}$ is photoelectric conversion efficiency of photovoltaic array; $\varepsilon$ is output efficiency of photoelectric inverter.

\subsection{Photovoltaic and Wind Power Combined Output Model.} Both photovoltaic power and wind power generation outputs have volatility and randomness, and their output conditions are closely related to weather conditions. In this paper, the Clay-Copula function is used to simulate the joint probability distribution of wind and photovoltaic power output; the formula is as follows:

$$
\begin{aligned}
& H\left(g_{w}, g_{\mathrm{pv}}\right)=C\left[F_{w}\left(g_{w}\right), F_{\mathrm{pv}}\left(g_{\mathrm{pv}}\right)\right] \\
& \quad=\max \left\{\left[\left(F_{w}\left(g_{w}\right)\right)^{-\varphi}+\left(F_{\mathrm{pv}}\left(g_{\mathrm{pv}}\right)\right)^{-\varphi}-1\right]^{1 / \varphi}, 0\right\},
\end{aligned}
$$

where $g_{w}, g_{\mathrm{pv}}$ are the wind power and photovoltaic power output; $F_{w}\left(g_{w}\right), F_{\mathrm{pv}}\left(g_{\mathrm{pv}}\right)$ are the probability distribution functions for wind and photovoltaic power output; $\varphi$ is the connection parameter, for wind and photovoltaic power outputs are not consistent with linear or normal assumptions. Therefore, the Spearman correlation coefficient is introduced in this paper.

In order to convert the edge distribution into corresponding ranks, the uniform probability distribution function is generated by transforming the cumulative probability density function $F(x), G(y) . F(x)$ obeys uniform distribution $U(0,1)$, for $r \in(0,1]$; the formula is as follows:

$$
P[F(x) \leq r]=P\left[x \leq F^{-1}(r)\right]=F\left[F^{-1}(r)\right]=r .
$$

Similarly, $G(y)$ is transformed into $(0,1]$ uniform distribution $V, U$ and $V$ are uniform distributions on $[0,1], E(U)=$ $E(V)=1 / 2$, and $\operatorname{var}(U)=\operatorname{var}(V)=1 / 12$. The formula for connection parameter $\varphi$ is as follows:

$$
\begin{aligned}
\varphi(X, Y) & =\varphi(F(X), G(Y))=\varphi(U, V) \\
& =\frac{\operatorname{cov}(U, V)}{\sqrt{\operatorname{var}(U)} \sqrt{\operatorname{var}(V)}} \\
& =12[E(U V)-E(U) E(V)] \\
& =12\left[E(U V)-\frac{1}{4}\right] \\
& =12 \int_{0}^{1} \int_{0}^{1} u v C(u, v)-3 .
\end{aligned}
$$

For a given wind and photovoltaic power plant output $\left(g_{w}, g_{\mathrm{pv}}\right)$, the paper can construct the joint distribution function $H\left(g_{w}, g_{\mathrm{pv}}\right)$; the formula of Spearman correlation coefficient $\varphi$ is shown as follows:

$$
\begin{aligned}
& \varphi\left(g_{w}, g_{\mathrm{pv}}\right) \\
& \quad=12 \int_{0}^{1} \int_{0}^{1} F_{w}\left(g_{w}\right) F_{\mathrm{pv}}\left(g_{\mathrm{pv}}\right) d H\left(g_{w}, g_{\mathrm{pv}}\right)-3 .
\end{aligned}
$$

2.4. Energy Storage Power Output Model. Storage power station is charging at night and discharging at daytime, which can effectively reduce the load curve peak valley difference, improve the stability of the grid, and promote wind and photovoltaic power connected grid.

$$
g_{k, s}^{\min }(t) \leq g_{k, s}(t) \leq g_{k, s}^{\max }(t)
$$

where $g_{k, s}^{\max }(t)$ and $g_{k, s}^{\min }(t)$ are the upper and lower limits of capacity for energy storage power plants; $g_{k, s}(t)$ is energy storage power plants capacity at time $t$.

When the energy storage power station is in the discharging state,

$$
g_{k, s}(t+1)=g_{k, s}(t)-\sum_{s=1}^{S} g_{k, s}^{d}(t)\left(1+\rho_{k, s}^{d}\right)
$$

When the energy storage power station is in the charging state,

$$
g_{k, s}(t+1)=g_{k, s}(t)+\sum_{k=1}^{N_{s}} g_{k, s}^{c}(t)\left(1+\rho_{k, s}^{c}\right)
$$

where $g_{k, s}^{d}(t)$ and $g_{k, s}^{c}(t)$ are the charging and discharging power of the energy storage station $k$ at time $t ; g_{k, s}(t+1)$ is energy storage station $k$ power capacity at time $t+1 ; \rho_{k, s}^{d}$ and 


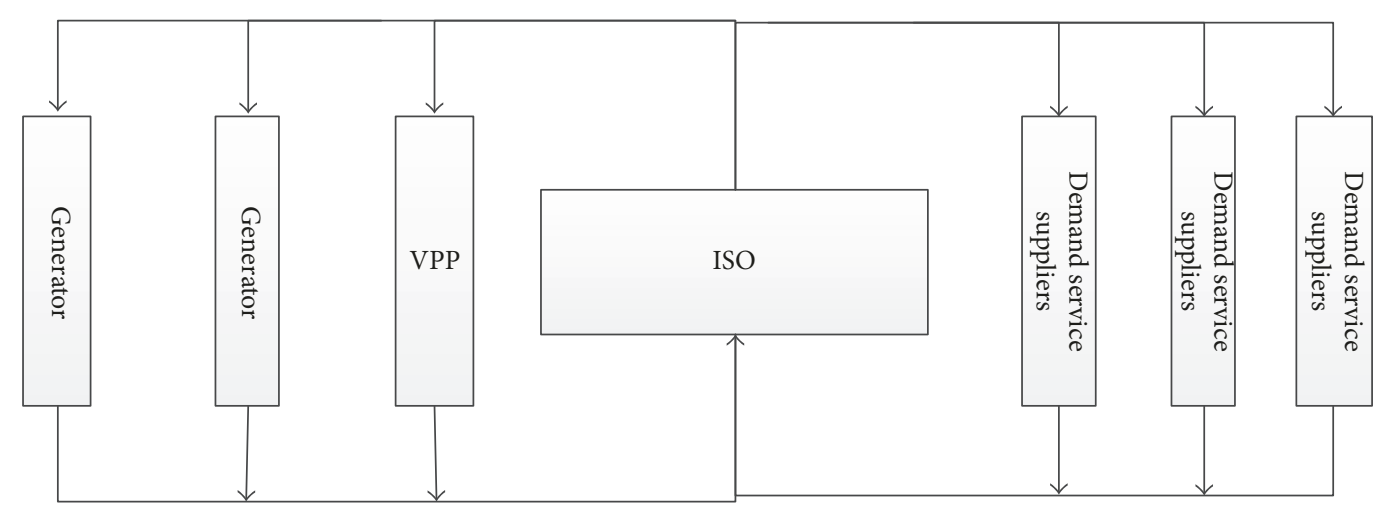

FIGURE 1: Bidding model in electricity market.

$\rho_{k, s}^{c}$ are discharging and charging loss of energy storage power station; Figure 1 shows bidding process of electricity market.

Figure 1 introduces a virtual power plant including wind, photovoltaic, and energy storage station to compete with traditional energy in the power market. How to realize the maximum benefit of the virtual power plant is the key problem.

\section{Bidding Strategy of Virtual Power Plant}

3.1. Wind and Photovoltaic Power Jointly Participate in Bidding. There are differences in the objective function of power market generators due to optimization emphasis, which mainly includes two aspects: technical performance index and economic index. When the virtual power plant wins the bid, the bidding output does not match the actual maximum output; it is necessary to purchase electricity from the realtime market, and VPP should compensate for economic losses.

When the virtual power plant participates in day-ahead power market bidding, $g_{w, \mathrm{pv}}(t)$ is VPP day-ahead bidding output at time $t, \Delta t$ is length of a single period, and $\mathrm{MCP}_{t}$ is the clearing price of electricity market in the period $t$. The revenue of VPP in the market can be expressed by the following formula:

$$
R_{w, \mathrm{pv}}=\sum_{t \in T} \mathrm{MCP}_{t} * g_{w, \mathrm{pv}}(t) * \Delta t
$$

Virtual power plants can use energy storage to provide reserve service for bidding output, which can reduce the deviation between bidding output and actual output of VPP.

\subsection{Objective Function}

3.2.1. Penalty Cost Minimization. Assuming that $\Delta g^{\text {up }}(t)$ and $\Delta g^{\text {down }}(t)$ are the deviations between bidding output and actual output of VPP, the corresponding penalty coefficients are $\omega^{\text {up }}(t)$ and $\omega^{\text {down }}(t) ; E^{c}$ is the penalty cost resulting from output deviation; the concrete formula is as follows:

$$
\begin{aligned}
& E^{c} \\
& =\sum_{t \in T}\left[\omega^{\text {up }}(t) * \Delta g^{\text {up }}(t)+\omega^{\text {down }}(t) * \Delta g^{\text {down }}(t)\right] \Delta t \\
& \Delta g^{\text {up }}(t)=g^{a}(t)-g_{s}(t)-g(t) \\
& \Delta g^{\text {down }}(t)=g(t)+g_{s}(t)+g^{a}(t),
\end{aligned}
$$

where $g^{a}(t)$ is the actual output of VPP; $g(t)$ is the bidding output of VPP; $g_{s}(t)$ is the output of energy storage.

3.2.2. Congestion Cost Minimization. Due to the restriction of transmission network, the power system will block during transmission; $E^{E}$ is congestion cost; the concrete formula is as follows:

$$
\begin{aligned}
E^{E}= & P_{\text {loss }}+\lambda_{1} \sum_{i=1}^{N_{D}}\left(V_{i}-V_{i, \mathrm{lim}}\right)^{2} \\
& +\lambda_{2} \sum_{i=1}^{N_{G}+N_{C}}\left(Q_{i}-Q_{i, \mathrm{lim}}\right)^{2} \\
P_{\text {loss }}= & \sum_{i=1, j \in i}^{N_{B}} G_{i j}\left[V_{i}^{2}+V_{j}^{2}-2 V_{i} V_{j} \cos \left(\delta_{i}-\delta_{j}\right)\right],
\end{aligned}
$$

where $P_{\text {loss }}$ is transmission loss; $N_{B}$ is the number of branches in the system; $N_{D}$ is the number of buses in the system; $N_{G}$ is the number of generators in the system; $N_{C}$ is the number of Static Var Compensator buses in the system; $\lambda_{1}$ and $\lambda_{2}$ are factors of penalty; $G_{i j}$ is conductance between line $i$ and $j ; V_{i}$ is the system voltage amplitude; $\delta_{i}$ is the system voltage phase angle; $V_{i, \text { lim }}$ is the system line voltage; $Q_{i, \text { lim }}$ is the system line capacity.

After introducing the congestion cost in the power system, the objective function can be expressed as follows:

$$
\max \pi=\sum_{w=1}^{N} R_{w, \mathrm{pv}}-E^{c}-\left[P_{\mathrm{loss}}+\lambda_{1} \sum_{i=1}^{N_{D}}\left(V_{i}-V_{i, \mathrm{lim}}\right)^{2}+\lambda_{i} \sum_{i=1}^{N_{G}+N_{C}}\left(Q_{i}-Q_{i, \mathrm{lim}}\right)^{2}\right]
$$


3.3. Constraint Condition. The constraints of this paper are as follows:

\section{(1) Load Balance}

$$
\begin{gathered}
\sum_{i=1}^{N_{G}} g_{i}(t) u_{i}(t)\left(1-\psi_{i}\right)+\sum_{s=1}^{S} g_{s}^{d}(t)\left(1-\rho_{s}^{d}\right) \\
+\sum_{w=1}^{W} g_{w, \mathrm{pv}}(t)\left(1-\varphi_{w}\right) \\
=L^{0}(t)-\Delta L(t)+\sum_{s=1}^{S} g_{s}^{c}(t)\left(1+\rho_{s}^{c}\right),
\end{gathered}
$$

where $N_{G}$ is the number of generators in the system; $S$ is the number of energy storage stations; $W$ is the amount of wind and photovoltaic power; $\psi_{i}$ is the unit power consumption rate; $\varphi_{w}$ is the wind and photovoltaic power consumption rate; $L^{0}(t)$ is system load demand; $\Delta L(t)$ is transmission loss of the system.

(2) Output Constraint of Energy Storage Station. In the whole scheduling period $T$, the relationship between the charging capacity and the discharge capacity of the energy storage power station is satisfied as follows:

$$
\begin{gathered}
\sum_{t=1}^{T}\left(g_{0}+\sum_{s=1}^{S} g_{k, s}^{c}(t)\left(1-\rho_{s, c}\right)-g(t)\right) \\
=\sum_{t=1}^{T} \sum_{s=1}^{S} g_{s}^{d}(t)\left(1+\rho_{s, d}\right),
\end{gathered}
$$

where $\rho_{s, c}$ and $\rho_{s, d}$ are charging and discharging efficiency of energy storage power station (0.95); during the same period, the energy storage station cannot charge and discharge simultaneously; the concrete formula is as follows:

$$
g_{s}^{d}(t) \cdot g_{s}^{c}(t)=0 .
$$

In order to meet the life requirements of energy storage station, the charging and discharging power cannot exceed $20 \%$ of the maximum capacity of the energy storage station; the concrete formula is as follows:

$$
\begin{aligned}
& 0 \leq g_{s}^{d}(t) \leq g_{s}^{d, \max }(t) \\
& 0 \leq g_{s}^{c}(t) \leq g_{s}^{c, \max }(t),
\end{aligned}
$$

where $g_{s}^{d}(t)$ is the charging capacity of energy storage power station; $g_{s}^{c}(t)$ is the discharging capacity of energy storage power station; $g_{s}^{d, \max }(t)$ and $g_{s}^{c, \max }(t)$ are the discharging and charging maximum capacity of energy storage station.

Considering the periodicity characteristics of energy storage devices and assuming that the stored energy is consistent at the beginning and end of the dispatch cycle, the concrete formula is as follows:

$$
g_{s, 0}=g_{s, \text { end }}
$$

(3) Positive and Negative Rotation Reserve Constraints. VPP provides positive and negative rotation reserve according to the requirements of power grid; the specific relationship is as follows:

$$
\begin{aligned}
& \sum_{i=1}^{N_{c}} I_{i}(t)\left[g_{i}^{\max }(t)-g_{i}(t)\right]+\sum_{k=1}^{N_{s}} g_{k, s}^{\max }(t) \geq R^{u}(t), \\
& g_{i}^{\max }(t)=\min \left[I_{i}(t-1) g_{i}^{\max }(t), g_{i}^{\max }(t-1)\right. \\
& \left.\quad+D_{i}^{\max }(t) \Delta t\right] I_{i}(t-1) \\
& R^{u}(t)=\alpha^{c} \sum_{i=1}^{N_{c}} g_{i}(t)+\alpha^{w} \sum_{j=1}^{N_{w}}\left(g_{j, w}(t), g_{j, w_{0}}(t)\right) \\
& \sum_{i=1}^{N_{c}} I_{i}(t)\left[g_{i}(t)-g_{i}^{\max }(t)\right]+\sum_{k=1}^{N_{s}} g_{k, s}^{\min }(t) \geq R^{d}(t) \\
& g_{i}^{\max }(t)=\max _{i}\left[I_{i}(t) g_{i}^{\min }(t), g_{i}^{\max }(t)-D_{i}^{\min }(t) \Delta t\right] \\
& \cdot I_{i}(t) \\
& \quad+\beta^{g} \sum_{j=1}^{N_{s}}\left(g_{k, s}(t), g_{k, s_{0}}(t)\right), \\
& R^{d}(t)=\beta^{w} \sum_{i=1}^{N_{w}}\left(g_{j, w}(t), g_{j, w_{0}}(t)\right)
\end{aligned}
$$

where $I_{i}(t)$ is spinning reserve demand coefficient of generating unit $i$ at time $t ; R^{u}(t)$ and $R^{d}(t)$ are up and down spinning reserve requirements of system at time $t ; g_{i}^{\max }(t)$ and $g_{i}^{\min }(t)$ are maximum and minimum output of unit $i$ at time $t ; g_{k, s}^{\max }(t)$ and $g_{k, s}^{\min }(t)$ are maximum and minimum output of energy storage power station $s$ at time $t ; D_{i}^{\max }(t)$ and $D_{i}^{\min }(t)$ are up and down ramping rate output of unit $i$ at time $t ; \alpha^{c}$ and $\alpha^{w}$ are positive rotation reserve rate and positive rotation reserve rate due to wind power integration; $\beta^{g}$ and $\beta^{w}$ are negative rotation reserve rates reduced by VPP integration and negative rotation reserve rate of energy storage station.

(4) Power Constraint of Transmission Network. The line power constraints between power systems can be expressed as follows:

$$
g_{\text {line }}^{\min } \leq g_{n}(t) \leq g_{\text {line }}^{\max },
$$

where $g_{n}(t)$ is the electric power of line transmission $n$ at time $t ; g_{\text {line }}^{\min }$ and $g_{\text {line }}^{\max }$ are the maximum and minimum electric power of line transmission $n$ at time $t$.

\subsection{Construction of Uncertainty Set}

3.4.1. VPP Output Uncertainty Set. The minimum and maximum output of wind and photovoltaic power at time $t$ can be expressed as follows:

$$
\begin{gathered}
g_{j, w}^{d}(t) \leq g_{j, w}(t) \leq g_{j, w}^{u}(t) \\
g_{m, \mathrm{pv}}^{d}(t) \leq g_{m, \mathrm{pv}}(t) \leq g_{m, \mathrm{pv}}^{u}(t) .
\end{gathered}
$$




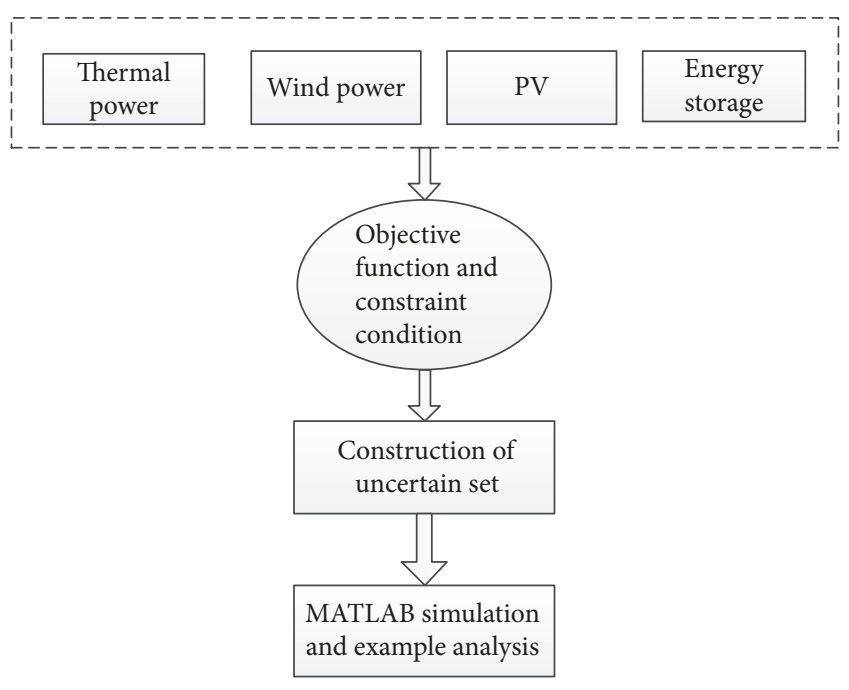

FIGURE 2: VPP bidding flow chart.

In this paper, the absolute predictive error of VPP is constrained by the 1-norm, and the parameter $\Gamma$ is the uncertainty coefficient.

$$
\sum_{j=1}^{N_{w}} \frac{\left|g_{j, w, \mathrm{pv}}^{a}(t)-g_{j, w, \mathrm{pv}}^{f}(t)\right|}{g_{j, w, \mathrm{pv}}^{f}(t)} \leq \Gamma .
$$

3.4.2. Electricity Price Uncertainty Set. Assume that $\lambda(t)$ is the day-ahead market energy price; $\lambda^{\text {up }}(t)$ is up reserve capacity price; $\lambda^{\text {down }}(t)$ is down reserve capacity price; $\lambda^{R}(t)$ is the spinning reserve capacity price; statistical analysis can be carried out according to historical data:

$$
\bar{\lambda}(t)-\hat{\lambda}(t) \leq \lambda^{R}(t) \leq \bar{\lambda}(t)+\hat{\lambda}(t),
$$

where $\bar{\lambda}(t)$ is mean value of electricity price; $\widehat{\lambda}(t)$ is fluctuation interval radius of electricity price.

\section{Case Study}

4.1. Solving Method. As an efficient commercial solver for linear programming, quadratic programming, and mixedinteger linear programming, CPLEX has been widely used in the optimization field. In this paper, AMPL/CPLEX is used to solve the robust optimization model of the energy storage station combined with wind and photovoltaic power. Figure 2 is the algorithm flow of this paper.

In the uncertain constraint programming model constructed by robust constraint, it cannot be directly solved. In terms of nonlinear terms, the computation complexity is high, and the multiobjective optimization problem is solved, but it is difficult to directly solve it. In order to solve the model, it can be transformed into a mixed-integer linear programming model and so on, so that the commercial software such as GAMS/CPLEX can be solved. The core points of the model transformation process include three parts: the deterministic equivalent representation of the
TABLE 1: Market clearing price for a typical month in PJM electricity market.

\begin{tabular}{lc}
\hline Time & Market clearing price \\
\hline 0 & 20.46 \\
1 & 16.99 \\
2 & 14.99 \\
3 & 15.22 \\
4 & 18.01 \\
5 & 25.80 \\
6 & 30.00 \\
7 & 31.51 \\
8 & 31.51 \\
9 & 31.64 \\
10 & 32.15 \\
11 & 31.92 \\
12 & 32.05 \\
13 & 32.20 \\
14 & 31.80 \\
15 & 31.57 \\
16 & 30.75 \\
17 & 30.00 \\
18 & 32.50 \\
19 & 33.40 \\
20 & 32.51 \\
21 & 32.27 \\
22 & 31.40 \\
23 & 28.61 \\
\hline &
\end{tabular}

stochastic constrained programming model, the normalization of multiple targets, and the linearization of the nonlinear constraints. By setting up different robust control coefficients, the simulation of the cooperative bidding process is carried out, and the optimal allocation of the joint cooperative bidding is obtained. The power system of this paper consists of 6 conventional thermal power units, two wind farms, two energy storage stations, and a photovoltaic power station, as shown in Figure 3.

4.2. Data Collection. In this paper, the cut-in speed is $4 \mathrm{~m} / \mathrm{s}$, the cut-out speed is $25 \mathrm{~m} / \mathrm{s}$, and the rated wind speed is $15 \mathrm{~m} / \mathrm{s}$; the total area of photovoltaic array in photovoltaic power station is $80000 \mathrm{~m}^{2}$, conversion efficiency is $14 \%$, maximum light intensity is $700 \mathrm{w} / \mathrm{m}^{2}$, minimum light intensity is $1 \mathrm{w} / \mathrm{m}^{2}$, and shape parameter and scale parameter of Beta distribution are 0.95 ; the corresponding penalty coefficient between bidding output and actual output of VPP is 0.95 , the rated capacity of two wind farms is $200 \mathrm{MW}$, the rated capacity of PV is $50 \mathrm{MW}$, and the rated capacity of energy storage stations is $50 \mathrm{MW}$; the maximum interrupting capacity of each line is $300 \mathrm{MW}$. The contract charge is $288 \mathrm{MW} \cdot \mathrm{h}, \Delta t$ is 1 , and Table 1 shows the mean market clearing price of PJM electricity market.

Assuming that the fluctuation interval radius of the dayahead market reserve service capacity price is $\pm 15 \%$, Table 2 
TABLE 2: Market real-time reserve capacity price.

\begin{tabular}{ll}
\hline Time & Price \\
\hline 0 & 15.57 \\
1 & 16.18 \\
2 & 16.44 \\
3 & 16.49 \\
4 & 16.52 \\
5 & 16.56 \\
6 & 16.56 \\
7 & 18.93 \\
8 & 23.26 \\
9 & 23.28 \\
10 & 23.65 \\
11 & 23.65 \\
12 & 23.76 \\
13 & 23.84 \\
14 & 23.87 \\
15 & 23.92 \\
16 & 26.45 \\
17 & 27.95 \\
18 & 28.02 \\
19 & 33.40 \\
20 & 32.51 \\
21 & 32.27 \\
22 & 31.40 \\
\hline & 28.61 \\
\hline
\end{tabular}

TABLE 3: Optimization results under different constraint violation probabilities.

\begin{tabular}{ccccc}
\hline Case & $\Gamma$ & $\begin{array}{c}\text { Constraint violation } \\
\text { probability }\end{array}$ & $\begin{array}{c}\text { Reserve service } \\
\text { income of energy } \\
\text { storage power } \\
\text { station }\end{array}$ & $\begin{array}{c}\text { Target } \\
\text { optimal value }\end{array}$ \\
\hline 1 & 0 & 53.64 & 5326.88 & 98153.541 \\
2 & 1 & 50 & 5115.65 & 94096.535 \\
3 & 3 & 41.36 & 4612.31 & 90249.164 \\
4 & 5 & 33.13 & 4049.50 & 82971.139 \\
5 & 12 & 11.5 & 3562.52 & 73302.540 \\
\hline
\end{tabular}

shows the mean reserve capacity price of PJM electricity market.

The virtual power plant bidding model needs to predict output of day-ahead wind and photovoltaic power. In order to facilitate the analysis, this paper uses the Clay-Copula function to simulate the joint output of photovoltaic and wind power.

4.3. Comparison Analysis of Methods. In Table 3, the optimal values of parameter values and objective functions and the income of the energy storage station are given at different constraint violation probability levels; different constraint violation probabilities correspond to different decision economic risks; from Table 3, the calculation results can be seen; with the decrease of constraint violation probability, the risk of virtual power plant bidding results violating the constraint is also smaller; the auction revenue and storage of the virtual power plant power plant revenues have declined; Figure 4 shows the output curve of units without optimization.

The risk preferences of different scenarios (scenario 1 to scenario 5) in Table 3 correspond to the robust control coefficient, and the constraint violation probability of the uncertainty coefficients of the virtual power plant decreases gradually.

The bidding strategy of virtual power plant under different scenarios is calculated in Figure 5.

It can be seen from the bidding output curve of VPP in Figure 5 that when the decision-maker's risk aversion increases, the VPP bidding output decreases. Accordingly, the reserve power of the energy storage station is reduced to stabilize the fluctuation of the VPP output; Figure 6 shows that the energy storage power station provides reserve power output curve for VPP with optimization.

Energy storage power participates in bidding of the reserve market, which requires coordination between 3 alternate types, so as to maximize the total revenue of the system.

Figures 7 and 8 show the reserve bidding output of the energy storage power station in the market bidding. The bidding strategy of virtual power plant will be affected by the change of energy storage station, wind turbine, and PV output.

In this paper, the robust bidding model of virtual power plant is established, and the robust control coefficient and the chance constrained parameter value are selected according to the risk preference of the decision-maker; Figure 9 is the energy storage power spinning reserve bidding capacity with optimization.

It can be seen from Figures 5-9 that the robust optimization method can improve the reliability of system with considering the uncertainty factors. With the increase of the robust coefficient, the efficiency of the energy storage equipment in VPP will be reduced. The robust optimization algorithm can improve the stability of the system, make the optimization result more in line with the actual situation, and make the decision more reasonable.

4.4. Sensitivity Analysis of Criteria. Bidding strategy of virtual power plant will be affected by the change of joint output of energy storage station and VPP.

As can be seen from Figure 10, with the output change of energy storage and wind and photovoltaic power, the sensitivity of the bidding strategy of the virtual power plant to the output of the energy storage station is greater than the sensitivity to the output of the wind and photovoltaic power. In addition to providing reserve for wind and photovoltaic power, the energy storage station can participate in the market bidding with the rich capacity, which can get reserve service fee from the system. When the system wind and photovoltaic power output increased, the wind and photovoltaic power output can participate in the market bidding with correlation of the output of the energy storage station. 


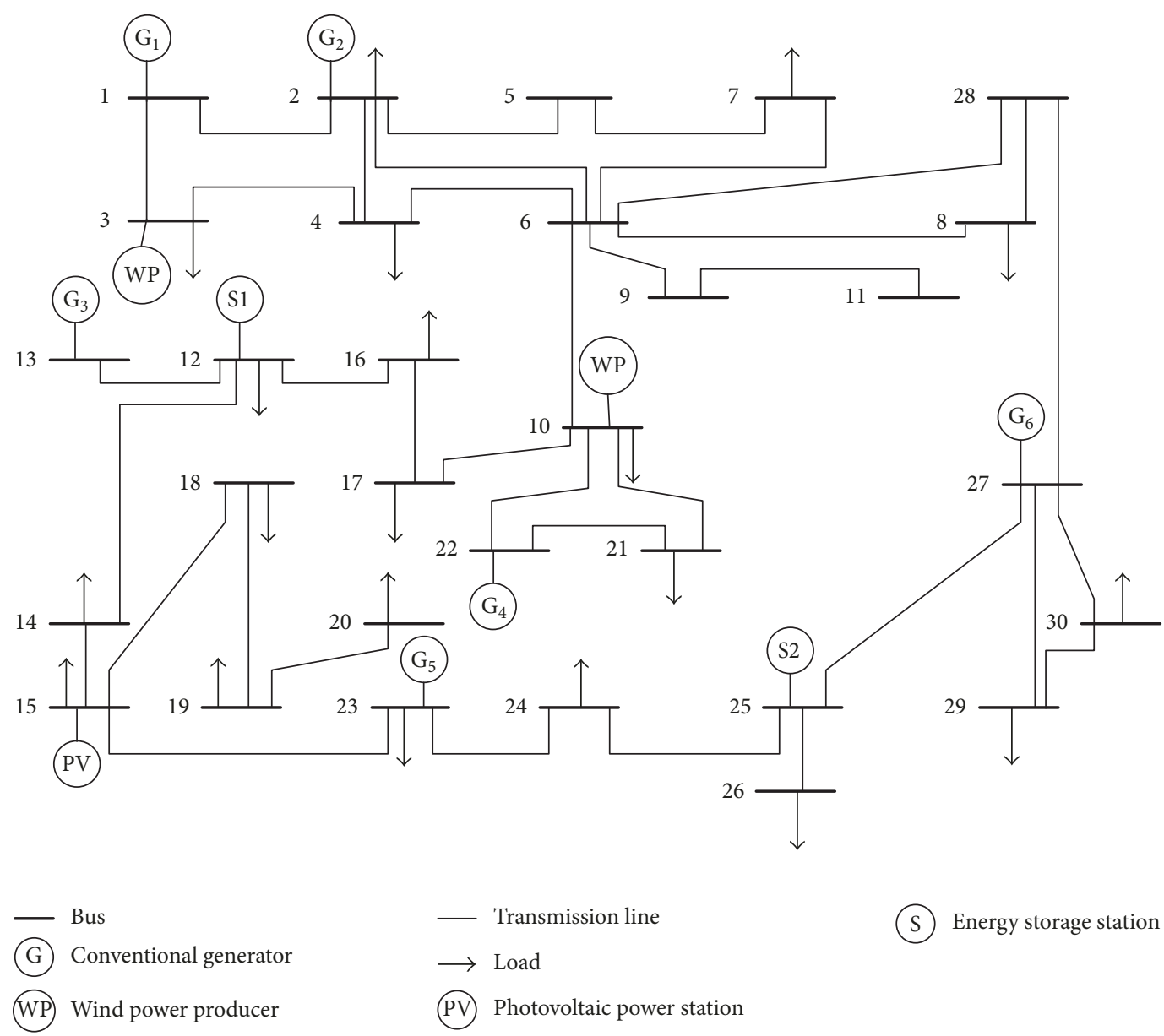

FIgURE 3: Topology distribution of 30 nodes in PJM system.

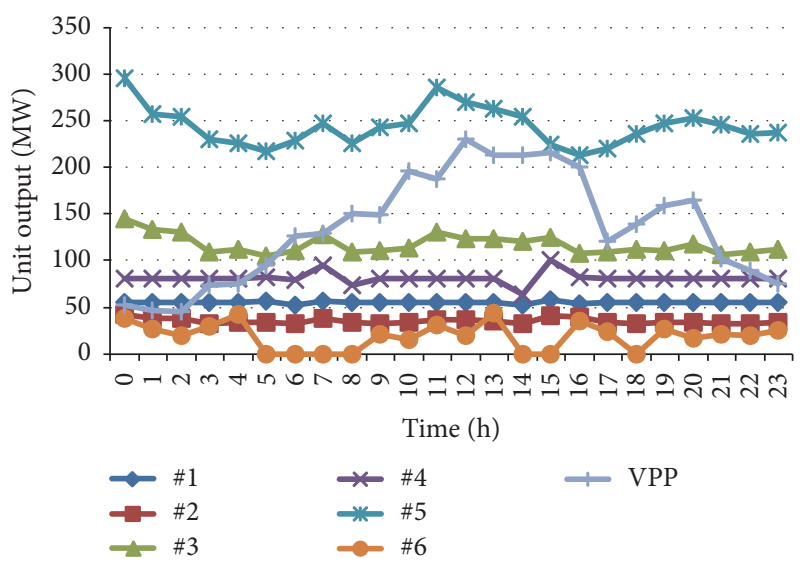

FIGURE 4: The output curve of each unit in the system.

\section{Conclusions}

In order to promote large-scale bidding for wind and photovoltaic power, which needs energy storage station providing reserve service, in this paper, a robust optimization bidding model for virtual power plants is proposed, which considers

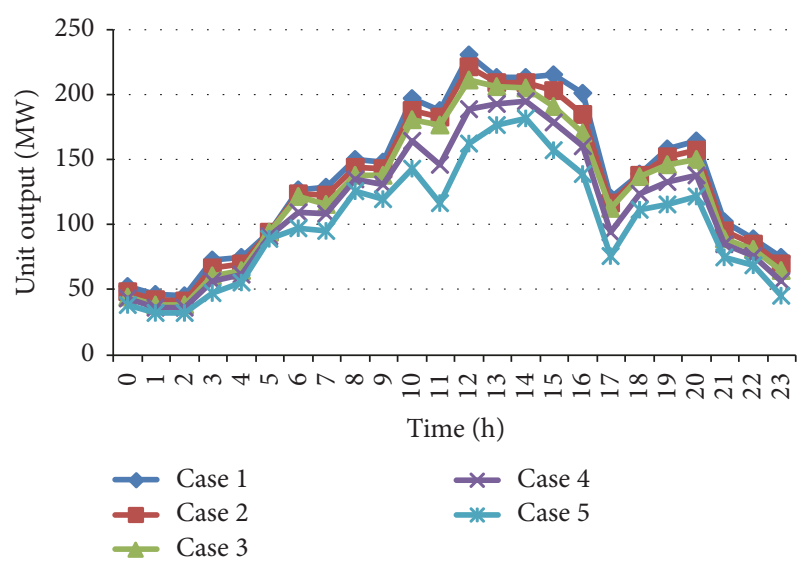

FIGURE 5: Bidding output variation curve of VPP.

the uncertainty of the wind and photovoltaic power output and the market price. Example results show the following:

(1) Construction of joint probability distribution of wind and photovoltaic power output is based on Clay-Copula function; the combined output model of wind and photovoltaic power is simulated. 


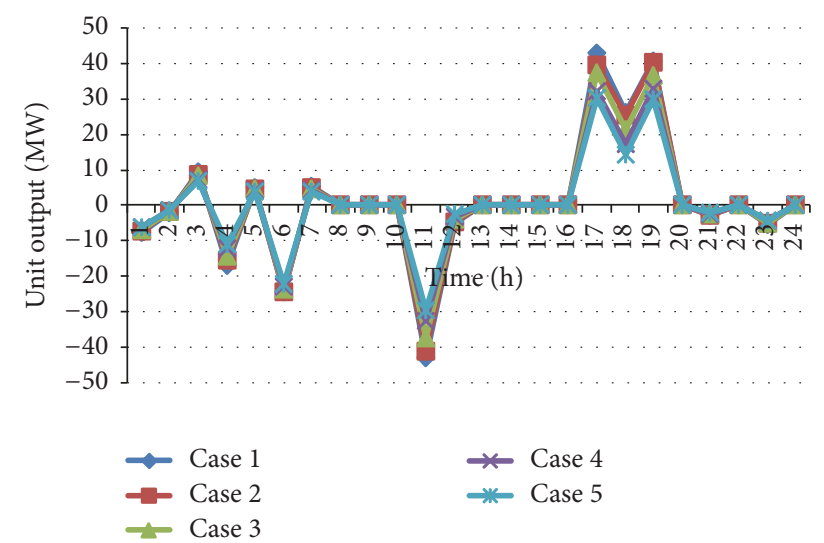

FIGURE 6: The energy storage power station provides reserve power output curve for VPP.

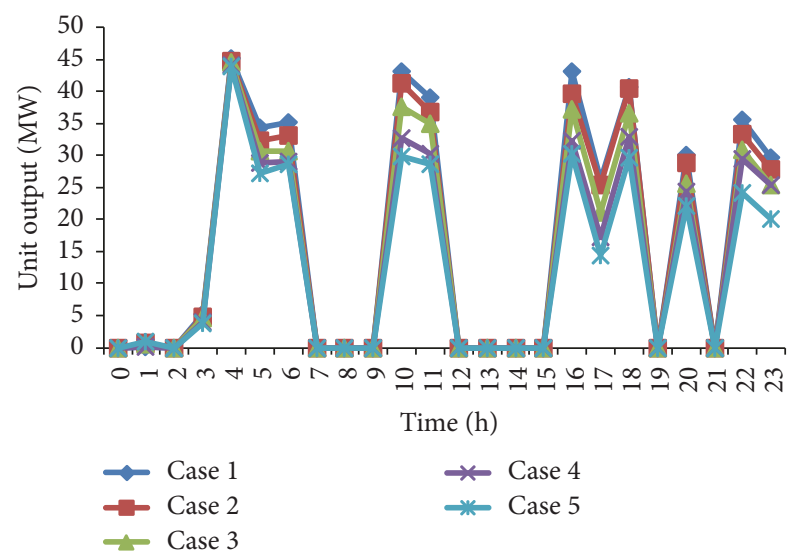

FIGURE 7: Energy storage power upregulation reserve bidding capacity.

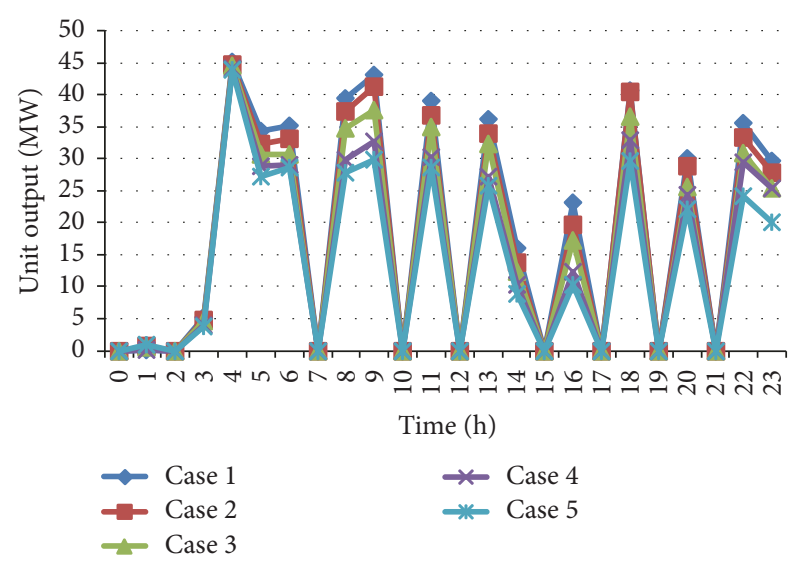

FIGURE 8: Energy storage power downregulation reserve bidding capacity.

As a result of the robust optimization, it is seen that the increase of wind and PV power capacity requires storage power station to provide reserve service. In order to promote the enthusiasm of the storage power station and the thermal power unit to participate in the coordination

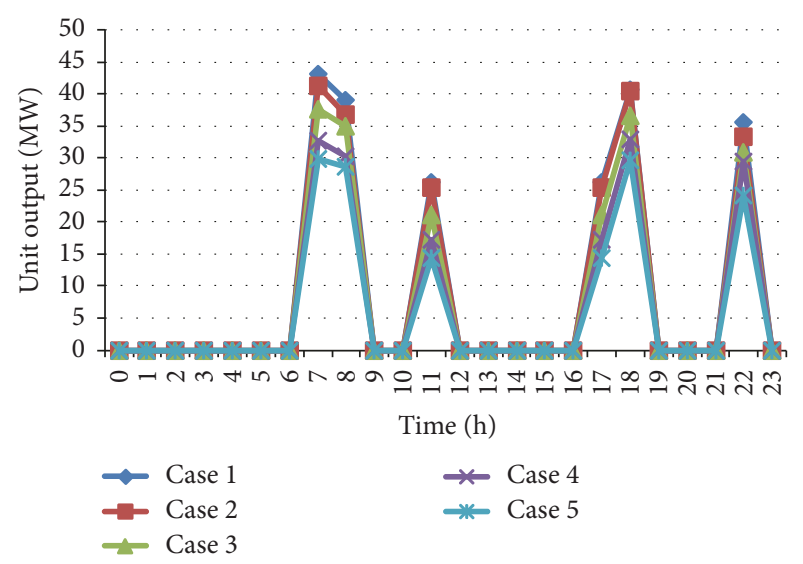

FIGURE 9: Energy storage power spinning reserve bidding capacity.

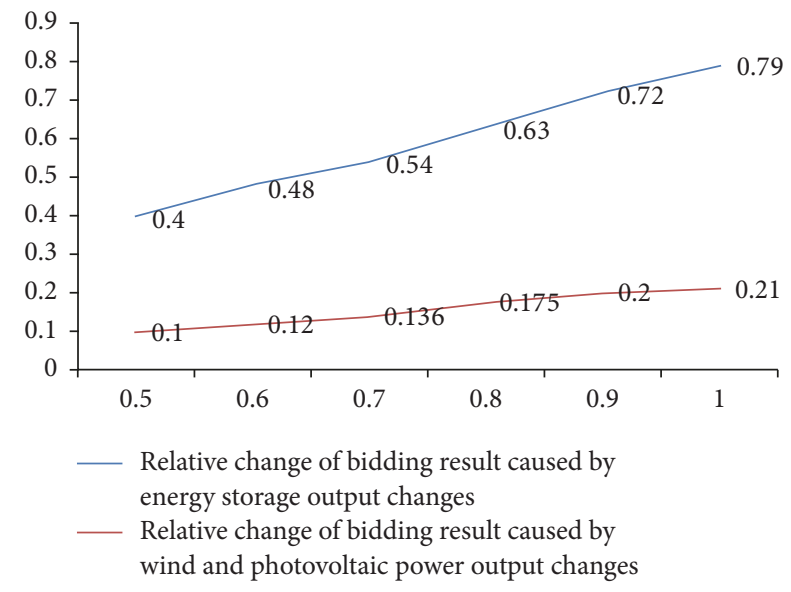

FIGURE 10: Effect on bidding result of energy storage and wind and photovoltaic power output changes.

of the wind power, it is necessary to arrange the output of the energy storage power station reasonably, which will realize the maximum income of the virtual power plant.

Intermittence of wind and PV power output is an important issue that cannot be avoided when participating in the bidding of the electricity market. The rapid development of energy storage power station provides a new way to stabilize the fluctuation of wind and PV power output. In this paper, a virtual power station with wind turbines, photovoltaic units, and energy storage power stations is constructed to participate in the collaborative bidding of electricity market; the robust optimization model solves the above problems, and an example is given to illustrate the feasibility and effectiveness of the proposed model and method.

\section{Conflicts of Interest}

The authors declare that there are no conflicts of interest regarding the publication of this paper. 


\section{Authors' Contributions}

It should be noted that the whole work was accomplished by the authors collaboratively. All authors read and approved the final manuscript.

\section{Acknowledgments}

This project is supported by the National Natural Science Foundation of China (71573084) and Beijing Municipal Social Science Foundation (16JDYJB044).

\section{References}

[1] B.-H. Zhang, J. Shao, X.-S. Wu, and K. Wang, "Unit commitment with wind farms using scenario tree and chanceconstrained programming," Power System Protection and Control, vol. 41, no. 1, pp. 127-135, 2013.

[2] X. Liu, "Economic load dispatch constrained by wind power availability: A wait-and-see approach," IEEE Transactions on Smart Grid, vol. 1, no. 3, pp. 347-355, 2010.

[3] M. Nick, R. Cherkaoui, and M. Paolone, "Optimal siting and sizing of distributed energy storage systems via alternating direction method of multipliers," International Journal of Electrical Power \& Energy Systems, vol. 72, pp. 33-39, 2015.

[4] S. S. Al Kaabi, H. H. Zeineldin, and V. Khadkikar, "Planning active distribution networks considering multi-DG configurations," IEEE Transactions on Power Systems, vol. 29, no. 2, pp. 785-793, 2014.

[5] O. Wu, C. Haozhong, Z. Xiubin et al., "Distribution network planning method considering distributed generation for peak cutting," Energy Conversion and Management, vol. 51, no. 12, pp. 2394-2401, 2010.

[6] P. S. Georgilakis and N. D. Hatziargyriou, "A review of power distribution planning in the modern power systems era: models, methods and future research," Electric Power Systems Research, vol. 121, pp. 89-100, 2015.

[7] P. Sadeghi-Barzani, A. Rajabi-Ghahnavieh, and H. KazemiKaregar, "Optimal fast charging station placing and sizing," Applied Energy, vol. 125, pp. 289-299, 2014.

[8] L. Zhipeng, W. Fushuan, and G. Ledwich, "Optimal planning of electric-vehicle charging stations in distribution systems," IEEE Transactions on Power Delivery, vol. 28, no. 1, pp. 102-110, 2013.

[9] D. Huajie, H. Zechun, and S. Yonghua, "Value of the energy storage system in an electric bus fast charging station," Applied Energy, vol. 157, pp. 630-639, 2015.

[10] S. Binato, M. V. F. Pereira, and S. Granville, "A new Benders decomposition approach to solve power transmission network design problems," IEEE Transactions on Power Systems, vol. 16, no. 2, pp. 235-240, 2001.

[11] X. Xiaogang, W. Biao, L. Xin, and F. Yanjun, "Study on electrical system multi-objective load dispatch optimization with wind farms considering wind power consumption," Renewable Energy Resources, vol. 34, no. 1, pp. 49-55, 2016.

[12] G. Muñoz-Delgado, J. Contreras, and J. M. Arroyo, "Joint expansion planning of distributed generation and distribution networks," IEEE Transactions on Power Systems, vol. 30, no. 5, pp. 2579-2590, 2015.

[13] A. Ben-Tal and A. Nemirovski, "Robust optimizationmethodology and applications," Mathematical Programming, vol. 92, no. 3, pp. 453-480, 2002.
[14] A. Ben-Tal and A. Nemirovski, "Robust solutions of linear programming problems contaminated with uncertain data," Mathematical Programming, vol. 88, no. 3, pp. 411-424, 2000.

[15] S. Haffner, L. F. A. Pereira, L. A. Pereira, and L. S. Barreto, "Multistage model for distribution expansion planning with distributed generation-part II: numerical results," IEEE Transactions on Power Delivery, vol. 23, no. 2, pp. 924-929, 2008.

[16] F. Wen and A. D. Kumar, "Optimal bidding strategies and modeling of imperfect information among competitive generators," IEEE Transactions on Power Systems, vol. 16, no. 1, pp. 15-21, 2001.

[17] Q. Ruozhen, H. Xiaoyuan, and Y. Hongtao, "Robust optimization model of multi-period inventory with uncertain demand distribution," Kongzhi yu Juece/Control and Decision, vol. 29, no. 9, pp. 1644-1648, 2014.

[18] F. Wen and A. K. David, "Optimal bidding strategies for competitive generators and large consumers," International Journal of Electrical Power \& Energy Systems, vol. 23, no. 1, pp. 37-43, 2001.

[19] H. Pandžić, J. M. Morales, A. J. Conejo, and I. Kuzle, “Offering model for a virtual power plant based on stochastic programming," Applied Energy, vol. 105, pp. 282-292, 2013.

[20] D. S. Kirschen, G. Strbac, P. Cumperayot, and D. P. De Mendes, "Factoring the elasticity of demand in electricity prices," IEEE Transactions on Power Systems, vol. 15, no. 2, pp. 612-617, 2000.

[21] Z. Haipeng, L. Hong, and L. Mingbo, "Robust optimal allocation of reactive power compensation in low voltage distribution networks considering uncertainty of photovoltaic generation," Power System Technology, vol. 40, no. 12, pp. 3880-3887, 2016.

[22] Q. Ling, L. Yi, D. Sai, W. Hailin, and Z. Weihong, "An improved light robust optimization model and its linear counterpart," Proceedings of the CSEE, vol. 36, no. 13, pp. 3365, 3463-3469, 2016.

[23] J. Feng, C. Xingguo, and W. Chaozhu, "Light robustness dispatch model for wind power integrated power system," Proceedings of the CSEE, vol. 36, no. 17, pp. 4600-4609, 2016.

[24] W. Qiang, Y. Shiyou, and L. Yuling, "A fast robust optimization methodology based on polynomial chaos and evolutionary algorithm for inverse problems," Proceedings of the CSEE, vol. 33, no. 3, pp. 171-175, 2013.

[25] D. Chao, W. Xifan, W. Xiuli, and S. Chengcheng, "Electricity market based on bilateral block bidding," Automation of Electric Power Systems, vol. 38, no. 13, pp. 28-32, 2014.

[26] Z. Peiyi and Z. Xinyan, "Research and application of genetic algorithm in bidding strategy for power market," Shanxi Electric Power, vol. 38, no. 8, pp. 21-24, 2010.

[27] C. Zheng, Y. Jiajia, J. Xiao-mingl et al., "A literature survey for pricing mechanisms and bidding strategies of renewable energy generation," Journal of North China Electric Power University, vol. 41, no. 2, pp. 89-98, 102, 2014.

[28] W. Jianxue, Z. Chenggang, W. Xiuli, and J. Jing, "A mixed bidding mode and its clearing algorithm for electricity market applications," Automation of Electric Power Systems, vol. 35, no. 7, pp. 28-33, 2011.

[29] L. Li, H. Yongxiu, and L. Yan, "Research on bidding strategies in electricity market based on gaming theory," Electric Power, no. 2, pp. 79-82, 2008.

[30] L. Yixin, G. Li, and W. Chengshan, "Optimal bidding strategy for microgrids in electricity distribution market," Power System Technology, vol. 41, no. 8, pp. 2469-2476, 2017. 
[31] Y. Long, L. Jichun, G. Hongjun, S. Ning, and L. Yang, "Study on the bidding strategy of comprehensive energy power retailer under the various user-price mechanisms," Power System Technology, vol. 38, no. 1, pp. 1-9, 2014.

[32] M. Carrión and J. M. Arroyo, "A computationally efficient mixed-integer linear formulation for the thermal unit commitment problem," IEEE Transactions on Power Systems, vol. 21, no. 3, pp. 1371-1378, 2006.

[33] E. Mashhour and S. M. Moghaddas-Tafreshi, "Bidding strategy of virtual power plant for participating in energy and spinning reserve markets-part I: problem formulation," IEEE Transactions on Power Systems, vol. 26, no. 2, pp. 949-956, 2011.

[34] A. F. Raab, M. Ferdowsi, E. Karfopoulos et al., "Virtual power plant control concepts with electric vehicles," in Proceedings of the 16th International Conference on Intelligent System Applications to Power Systems, pp. 1-6, IEEE, Hersonissos, Greece, September 2011. 


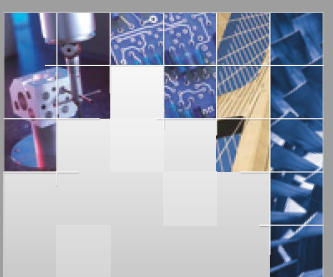

\section{Enfincering}
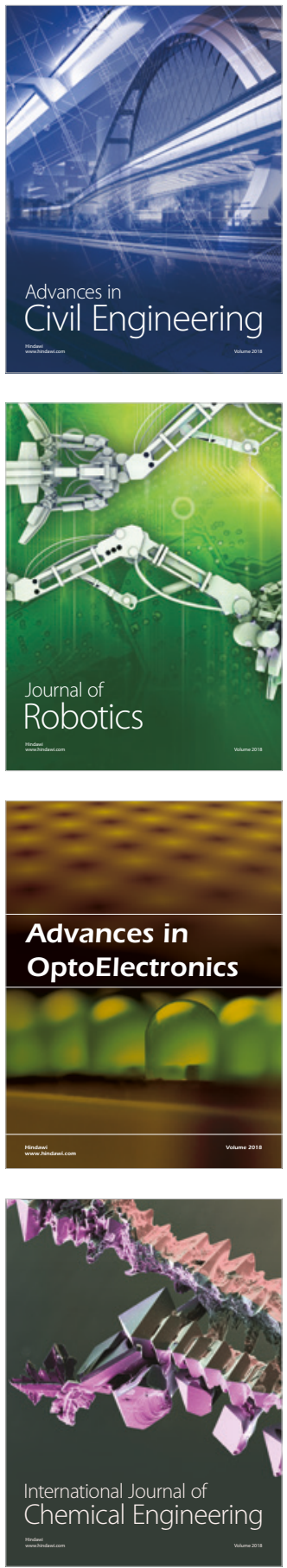

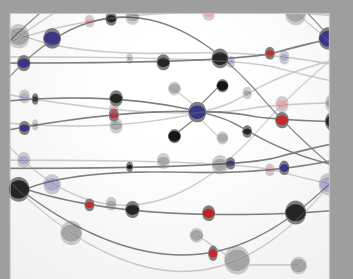

\section{Rotating \\ Machinery}

The Scientific World Journal

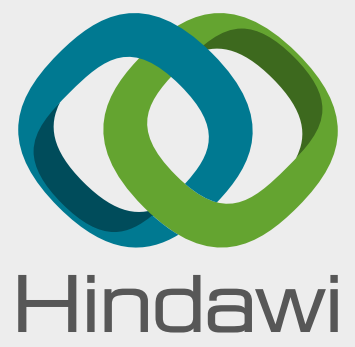

Submit your manuscripts at

www.hindawi.com
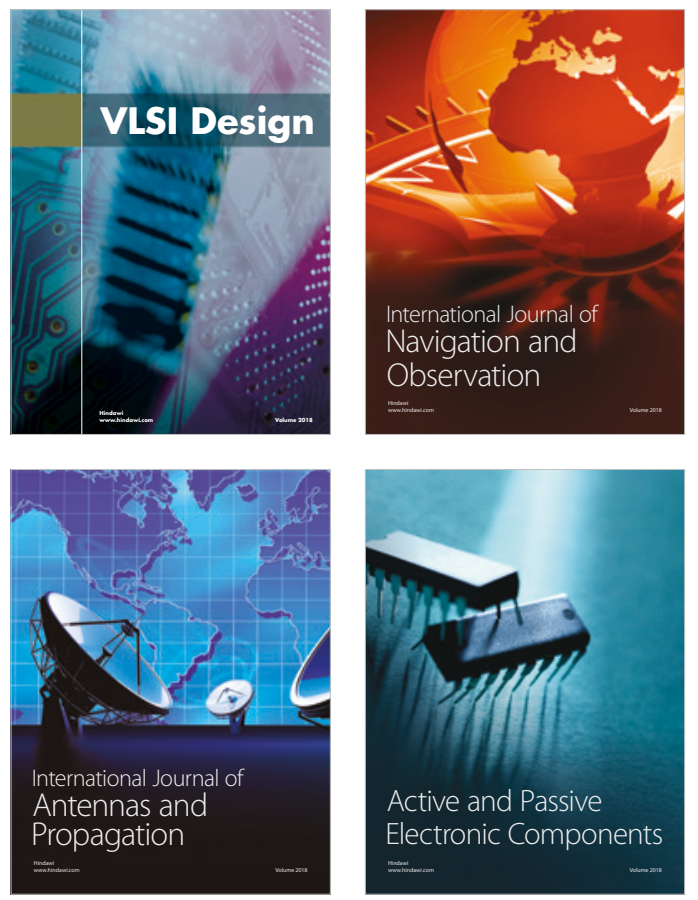
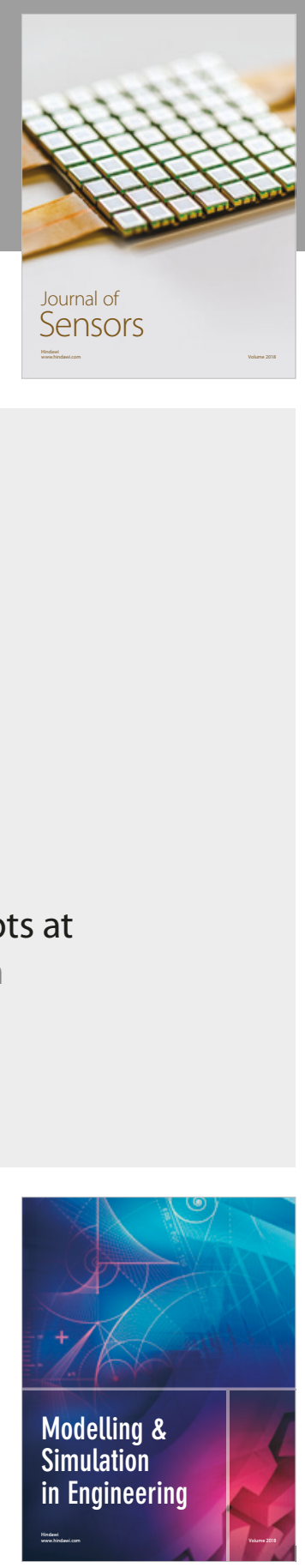

\section{Advances \\ Multimedia}
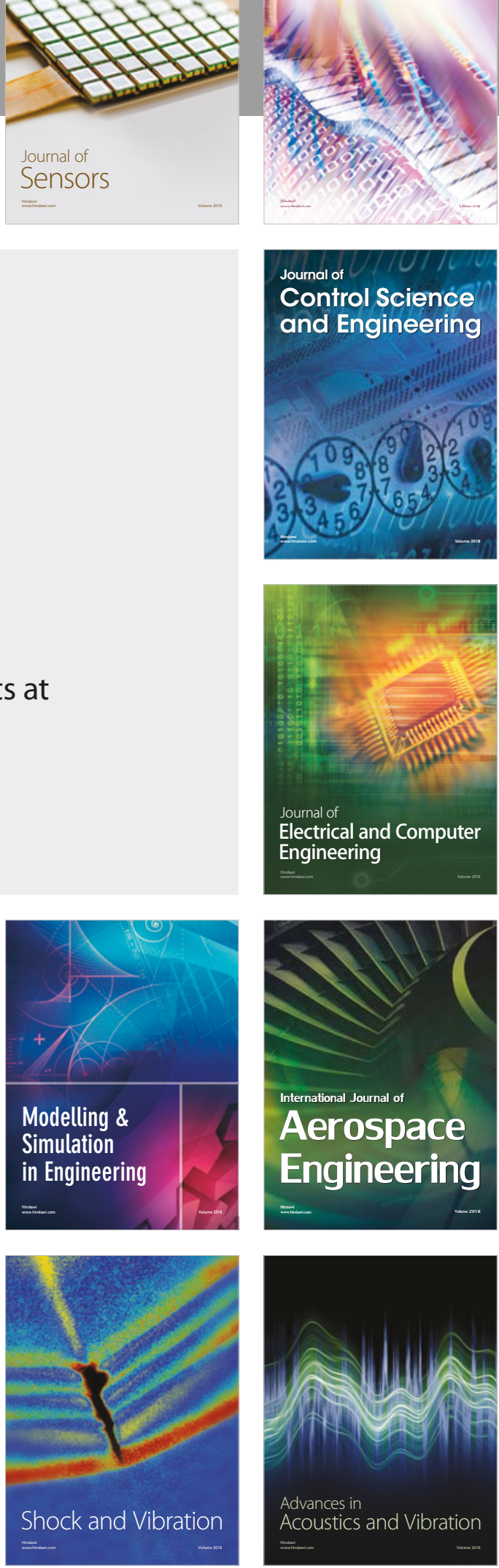